\title{
A Constituição de Ambientes Colaborativos de Aprendizagem em Ações de Formação Continuada: abordagem experimental com GeoGebra
}

\section{The Constitution of Collaborative Learning Environments in Continuing Education Actions: experimental approach with GeoGebra}

\author{
Maria Teresa Zampieri* \\ ORCID iD 0000-0002-6656-2538 \\ Sueli Liberatti Javaroni** \\ ORCID iD 0000-0002-1948-4346
}

\begin{abstract}
Resumo
O objetivo deste artigo é discorrer sobre duas ações de formação continuada e como elas se constituíram em ambientes colaborativos de aprendizagem. Tais ações focalizaram a realização de atividades experimentais com o software GeoGebra, nas quais participaram pesquisadores e professores de Matemática da Educação Básica. Ademais, alguns dados empíricos são apresentados e discutidos aqui, com a finalidade de elucidarmos as discussões acerca de duas dessas atividades. Tais ações de formação continuada compõem o cenário de investigação de uma pesquisa de doutorado de cunho qualitativo, que está em desenvolvimento, vinculada a um projeto temático de grande envergadura que vem sendo realizado dentro do Grupo de Pesquisa em Informática, outras Mídias e Educação Matemática (GPIMEM). Uma das ações aconteceu na cidade de Bauru/SP e a outra na cidade de Coimbra, em Portugal. As atividades abordadas nessas ações, assim como nas demais desenvolvidas em outros projetos de pesquisa do grupo, de modo geral, tem um enfoque teórico-metodológico de natureza experimental. Conclui-se que os professores, ao mesmo tempo em que realizaram tais atividades e opinaram acerca de outros conteúdos matemáticos que poderiam ter sido contemplados nelas, estudaram as funcionalidades do software, tecendo críticas às abordagens propostas, culminando em sugestões de adaptações, tornando-as viáveis para serem aplicadas em suas respectivas salas de aula. Por fim, evidencia-se que a participação em tais ações lhes possibilitou vislumbrar maneiras para se constituir ambientes colaborativos de aprendizagem também em seus respectivos contextos de trabalho.
\end{abstract}

Palavras-chave: Educação Matemática. Tecnologias Digitais. Ensino e Aprendizagem de Conteúdos Matemáticos.

\section{Abstract}

\footnotetext{
" Doutora em Educação Matemática pela Universidade Estadual Paulista "Júlio de Mesquita Filho" (UNESP). Pesquisadora de Pós-Doutoramento, Universidade Estadual Paulista "Júlio de Mesquita Filho", Rio Claro, São Paulo, Brasil. Endereço para correspondência: Rua Antonio Carlos Galvão de Moura Lacerda, 97, Nova Piracicaba, Piracicaba, São Paulo, Brasil, CEP: 13405-171. E-mail: maite.zampieri@gmail.com.

** Doutora em Educação Matemática pela Universidade Estadual Paulista "Júlio de Mesquita Filho" (UNESP). Professora do Departamento de Matemática, Faculdade de Ciências da Universidade Estadual Paulista "Júlio de Mesquita Filho" (UNESP), Bauru, São Paulo, Brasil. Endereço para correspondência: Av. Luiz Edmundo Carrijo Coube, 14-01, Vargem Limpa, Bauru, São Paulo, Brasil, CEP: 17033-360. E-mail: suelilj@ fc.unesp.br.
} 
The aim of this article is to discuss two actions of continuing education, and how they constituted themselves in collaborative learning environments. These actions focused on the accomplishment of experimental activities with the GeoGebra software, in which researchers and teachers of Basic Education Mathematics participated. In addition, some empirical data are presented and discussed here, in order to elucidate the discussions about two of these activities. These actions of continuing education compose the research scenario of a qualitative doctoral research that is under development, linked to a thematic project of large scale that has been carried out within the Research Group in Informatics, Other Media and Mathematics Education (GPIMEM). One of the actions happened in the city of Bauru/SP, and the other in the city of Coimbra, Portugal. The activities addressed in these actions, as well as those developed in the group's other research projects, generally have a theoreticalmethodological approach of an experimental nature. It is concluded that teachers, while performing such activities and opining about other mathematical contents that could have been contemplated in them, studied the software functionalities, criticizing the proposed approaches, culminating in suggestions of adaptations, making them viable to be applied in their respective classrooms. Finally, it is evident that participation in such actions enabled them to glimpse ways to create collaborative learning environments in their respective work contexts.

Keywords: Mathematics Education. Digital Technologies. Teaching and Learning of Mathematical Contents.

\section{Introdução}

Pesquisas acerca do uso de tecnologias digitais (TD) nas aulas de Matemática, como as de Almeida (2008), Chinellato (2014), Oliveira (2014) e Peralta (2015) destacaram alguns dos motivos que levam o professor a não utilizar dessas TD em sua prática, sendo um deles a formação inicial ou continuada, que por vezes se mostra insuficiente para prepará-lo para o uso. Assim, como uma tentativa de colaborar para a mudança desse cenário, pesquisadores vinculados ao projeto temático Mapeamento do uso das tecnologias de informação nas aulas de Matemática do estado de São Paulo ${ }^{1}$, vêm, desde o segundo semestre do ano de 2014, desenvolvendo ações de formação continuada com professores que ensinam Matemática em escolas públicas paulistas vinculadas às diretorias de Ensino de Bauru, Limeira, Presidente Prudente, São José do Rio Preto, Registro e Guaratinguetá, totalizando assim 6 (seis) ações voltadas para o fomento desse uso.

Além dessas, uma sétima ação ocorreu na cidade de Coimbra, Portugal. Em todas essas ações, os conteúdos abordados com os vários professores eram de interesse do grupo constituído. Porém, em todas elas, a tônica era a realização de atividades experimentais com o software dinâmico GeoGebra ${ }^{2}$. A primeira dessas ações aconteceu na cidade de Bauru, no segundo semestre de 2014, em formato de um curso de extensão universitária com carga horária de 40 horas, desenvolvido com professores que ensinam Matemática na Educação Básica, vinculados à Diretoria de Ensino da região dessa referida cidade. Tal curso constitui-

\footnotetext{
1 Esse projeto foi aprovado sob no 16429 no Edital 049/2012/CAPES/OBEDUC/INEP e coordenado pela segunda autora desse trabalho Para uma maior fluidez na leitura, nos referiremos a ele apenas como "Mapeamento".

${ }^{2}$ https://www.geogebra.org/. Último acesso em 13.06.2017.
} 
se como a primeira edição dos cursos de formação continuada para professores, que vêm sendo realizados pelo projeto Mapeamento. Esse projeto é desenvolvido dentro do GPIMEM, e conta ainda com o apoio de colaboradores oriundos de diferentes segmentos, como: alunos de iniciação científica (IC), alunos de mestrado e doutorado, professores de Matemática da Educação Básica e professores universitários.

Todos colaboram com o planejamento e a execução das ações de formação continuada promovidas pelo projeto, que por sua vez, envolvem o planejamento e o desenvolvimento de cursos de extensão universitária, ofertados aos professores da rede estadual pública, lotados nas diretorias de ensino situadas nas cidades anteriormente mencionadas. As duas ações que trazemos nesse trabalho foram conduzidas pela primeira autora, sob a orientação da segunda, já que elas compõem o cenário de investigação da pesquisa de doutoramento da primeira, que por sua vez, é vinculada ao projeto Mapeamento.

$\mathrm{Na}$ condução dessa ação que ocorreu na cidade de Bauru, a doutoranda ainda contou com o apoio da coordenadora desse projeto (segunda autora desse artigo), com duas alunas de IC do curso de graduação em Matemática da UNESP de Bauru, e pela professora coordenadora do núcleo pedagógico (PCNP) da área de Matemática, lotada na Diretoria de Ensino de Bauru. O propósito de tal ação foi de explorar conteúdos matemáticos que constam no currículo referente à disciplina de Matemática, dos Anos Finais do Ensino Fundamental com o uso das TD. A dinâmica de trabalho se deu da seguinte forma: os professores realizavam, em duplas ou em trios, cerca de três a quatro atividades a cada encontro. Após a realização de cada uma, acontecia um debate, para que eles tecessem suas considerações acerca das abordagens propostas e trocassem ideias buscando pensar em adaptações para tais atividades.

Entretanto, destacamos ainda que a proposta do curso foi flexível o bastante para que os professores se sentissem a vontade para expor suas ideias e opiniões, trabalhando uns com os outros, colaborativamente. Além disso, visando fomentar essa postura colaborativa, dentro de todas as atividades que já havíamos preparado previamente acerca dos conteúdos do currículo, abordamos apenas àquelas cujos conteúdos foram elencados por eles no primeiro encontro, explorados com o software que eles optaram por estudar, que por sua vez, foi o GeoGebra. Um pedido que fizemos aos professores foi que eles sempre realizassem as atividades pensando nos perfis de aprendizagem de seus alunos, buscando sempre adaptá-las para esse fim. Essa sugestão foi totalmente seguida por eles, culminando em momentos de aprendizagem e muitas discussões, conforme será retratado mais adiante (JAVARONI; 
ZAMPIERI, 2015).

Já a outra ação, cuja proposta e dinâmica de trabalho se deram de modo análogo a anterior, também levando em consideração os conteúdos e o software de interesse dos professores, foi fruto do estágio de doutorado no exterior realizado pela doutoranda, sob a supervisão do Prof. Dr. Jaime Carvalho e Silva, da Universidade de Coimbra, em Portugal. Para buscar estabelecer um intercâmbio de ideias entre esses pesquisadores, surgiu essa oportunidade de estágio, com o propósito de desenvolver uma ação de formação continuada de professores que ensinam Matemática, na cidade de Coimbra, voltada para o uso das TD, totalizando uma carga horária de 25 horas, sendo conduzida pela doutoranda e pelo supervisor do estágio, no primeiro semestre de 2016.

Essa pesquisa de doutorado, assim como as demais vinculadas ao projeto Mapeamento, tem o foco nos indivíduos, no modo como interagem entre si, com as tecnologias que utilizam e com os ambientes em que estão inseridos. Nesse sentido, tais pesquisas seguem uma abordagem metodológica qualitativa (JAVARONI; ZAMPIERI, 2015). $\mathrm{Na}$ pesquisa de doutoramento, cujos recortes estamos tratando aqui, os procedimentos utilizados para a produção dos dados foram: a gravação em vídeos de todos os encontros dos dois cursos desenvolvidos, a elaboração e aplicações de atividades experimentais acerca de conteúdos matemáticos, elaboração do caderno de campo da pesquisadora e aplicação de questionários aos sujeitos participantes da pesquisa.

Neste artigo, especificamente, temos o propósito de discutir como essas duas ações, a de Bauru e a de Coimbra, voltadas para a realização de atividades experimentais com o software GeoGebra e que envolveram a participação de pesquisadores e professores que ensinam Matemática, culminaram na constituição de ambientes de aprendizagem. Para isso, visamos apresentar e discutir dados empíricos, destacando algumas das discussões ocorridas durante e após o desenvolvimento de duas atividades, para retratar as ideias de adaptações que vieram à tona e o aprofundamento dos educadores acerca das funcionalidades desse software, tendo como pano de fundo as abordagens propostas nas atividades e o contexto de trabalho de cada professor. Assim, os dados que serão aqui discutidos são provenientes da videogravação e do caderno de campo. A seguir, traremos alguns aspectos acerca do GeoGebra e dos aportes teóricos com os quais dialogamos ao longo desse artigo.

\section{GeoGebra, ambientes colaborativos de aprendizagem e atividades experimentais}


O software dinâmico GeoGebra, de livre acesso, teve sua origem ao longo do desenvolvimento da tese de doutoramento do pesquisador Markus Honenwarter, no início da década passada (BOTANA et al, 2015). Desde então, esse software vem sendo aprimorado continuamente, expandindo cada vez mais suas funcionalidades e atraindo, na mesma proporção, o interesse de um público composto por professores de Matemática que atuam em todos os níveis de escolaridade e também de estudantes dentro destes diferentes níveis. $\mathrm{O}$ GeoGebra integra janela de álgebra, janela de visualização, planilha, campo "entrada" para a inserção de funções ou fórmulas, dentre outros recursos, sendo possível visualizá-los e manuseá-los na mesma tela, conforme mostra a figura 1 a seguir:

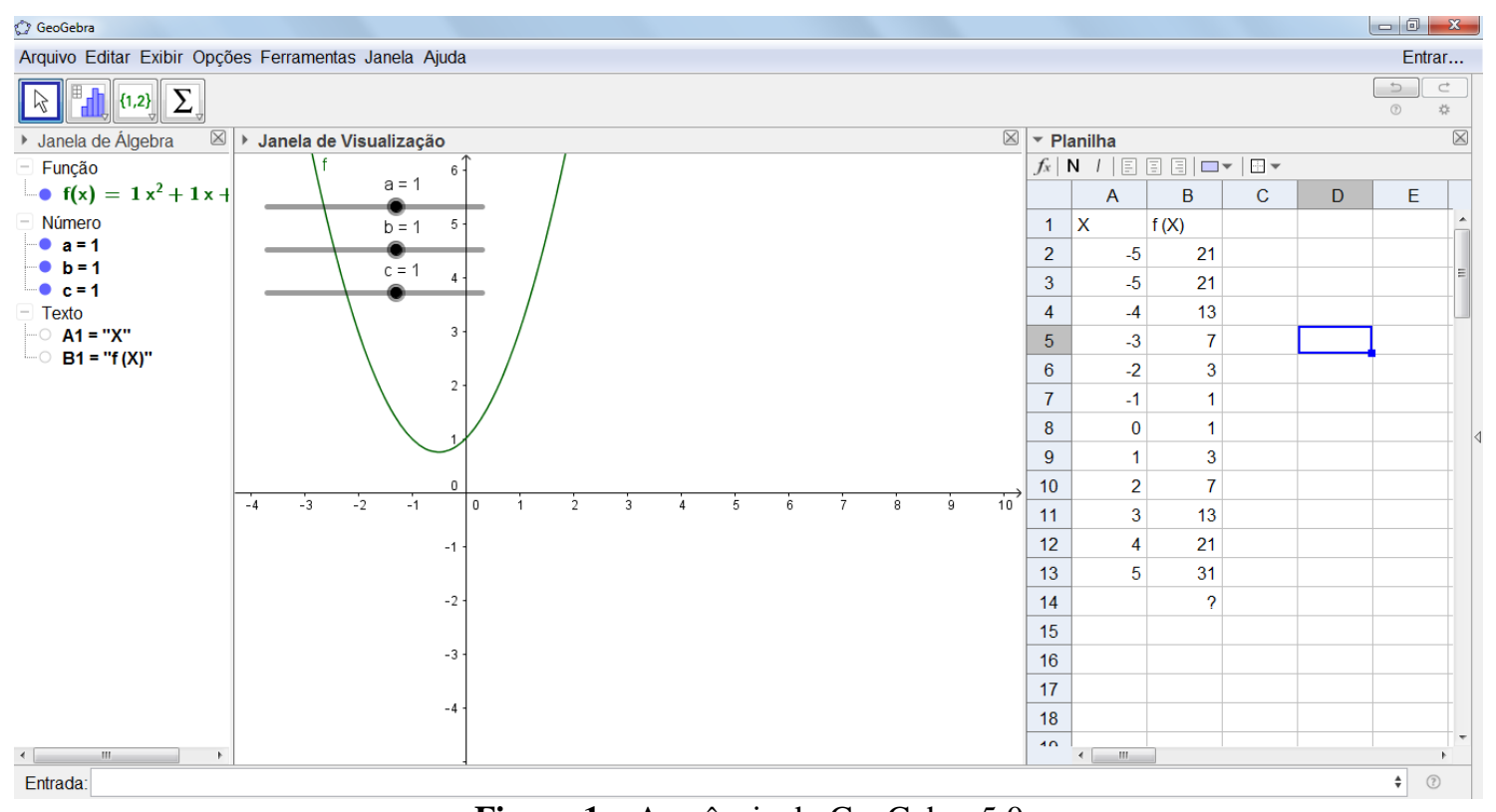

Figura 1 - Aparência do GeoGebra 5.0

Fonte: Dados da pesquisa de doutorado de Zampieri (2018).

Em um primeiro momento, esse software havia sido desenvolvido visando motivar a experimentação entre estudantes, sem levar em consideração o desenvolvimento de raciocínios mais formais, segundo Botana et al. (2015). No entanto, de acordo com esses mesmos autores, desde que foram incorporadas as ferramentas de dedução automatizadas em 2014, sendo uma delas o comando booleano, que retorna verdadeiro ou falso as correlações que envolvem paralelismo, ortogonalidade, colinearidade, igualdade, etc. ele passou então a trazer uma nova gama de cenários para os processos de ensino e aprendizagem.

Assim, atualmente, os desenvolvedores desse software vêm trabalhando em um projeto que visa a incorporação e testes de diferentes demonstrações automatizadas para conteúdos de geometria. Segundo os autores, muitos teoremas complexos já podem ser demonstrados por esse software, cuja consequência é o fomento de muitas e novas formas de utilizar o GeoGebra em sala de aula (BOTANA et al., 2015). Um exemplo disso, segundo eles, é que, 
quando uma dada construção é realizada no software, há a possibilidade de que seja feita uma identificação automática de alguma propriedade que caracteriza tal construção. Há ainda a possibilidade de ser dado, como parte do feedback do software, um contraexemplo de alguma relação matemática que não é sempre verdadeira.

Além dessa nova vertente contemplada pelo software, atualmente ele também vem impulsionando a constituição de ambientes de aprendizagem, conforme destacam Santos e Trocado (2016). Esses autores argumentam que ele possibilita produzir e ensinar Matemática colaborativamente. Ou seja, eles levantam possibilidades para que pequenos grupos de alunos, ou ainda, pequenos grupos envolvendo alunos e professores, se engajem na resolução de problemas que envolvam discussão e reflexão, interagindo com o GeoGebra, principalmente se pautando nesses novos recursos de automatização implementados, que propiciam um feedback ainda mais rápido ao usuário.

Eles destacam as diversas páginas na internet que a comunidade do GeoGebra mantém, em distintos idiomas, as quais "têm criado uma grande rede de contatos, produzindo e compartilhando materiais no GeoGebra tube ${ }^{3,4}$ (SANTOS; TROCADO, 2016, p. 16, tradução nossa). Contudo, os autores refletem acerca de uma indagação: se seria possível que o software GeoGebra se constituísse, por si só, em um sistema de gestão de aprendizagem. Respondendo positivamente a esse questionamento, eles argumentam sobre possibilidades de se criar ambientes colaborativos de aprendizagem com o uso desse software.

Para reforçar tais possibilidades, eles discorrem acerca de projetos de pesquisa que caminham nessa direção, sendo um deles o laboratório de geometria na rede, cujo objetivo é a construção de um ambiente colaborativo virtual, que integra softwares dinâmicos, mais especificamente o GeoGebra, e demonstrações de teoremas automatizadas (SANTOS; TROCADO, 2016). Em relação ao primeiro projeto, o laboratório de geometria em rede, segundo Santos e Quaresma (2013), envolve a realização de atividades de cunho investigativo com softwares dinâmicos, sendo um deles o GeoGebra, por meio de uma plataforma virtual que contempla: uma combinação de momentos síncronos e assíncronos; a constituição de grupos para a realização de diferentes atividades sobre conteúdos geométricos, permitindo a interação entre os usuários da plataforma; e abarca os perfis de visitante, aluno, professor e administrador. Assim, segundo os autores, o propósito geral desse projeto é "o de

\footnotetext{
${ }^{3}$ Site do GeoGebra tube: https://www.geogebra.org/material/show/id/1303715. Último acesso em 24.05.2017.

${ }^{4}$ Trecho original em inglês: “...has created a large contacts network, produces and shares materials in GeoGebra tube" (SANTOS; TROCADO, 2016, p. 16).
} 
disponibilizar um recurso a ser utilizado numa sala de aula, num ambiente de aprendizagem mediado e acompanhado pelo professor" (SANTOS; QUARESMA, 2013, p. 34).

Entretanto, mesmo sem uma plataforma para mediar o desenvolvimento de atividades com softwares dinâmicos em sala de aula, ainda nos parece possível a criação de ambientes colaborativos, em que alunos aprendam uns com os outros e os professores avaliem a aprendizagem de seus alunos nesse processo. Isso pode acontecer se as potencialidades de tais softwares forem aproveitadas em atividades de caráter experimental, de forma a valorizar a criação e exploração de conjecturas e as discussões em grupos.

O GeoGebra, por exemplo, por ser um software de fácil acesso, gratuito, de interface amigável, dinâmico e com todas as outras características já mencionadas anteriormente, tem potencialidades que podem ser muito bem exploradas para o desenvolvimento de atividades embasadas na experimentação. Seja em laboratórios de informática ou mesmo em sala de aula, por meio do trabalho com as versões do GeoGebra para tablets e smartphones $^{5}$, se houver colaboração entre alunos e professores, por meio de atividades, cuja abordagem tenha uma sinergia com as potencialidades de tal software, então, no cerne desse trabalho, há possibilidades para a ocorrência de uma aprendizagem mútua entre os envolvidos. Assim, essa dinâmica de aula se caracterizaria como um ambiente colaborativo de aprendizagem, pois traria oportunidades para discussões e reflexões ao longo da realização das atividades.

No nosso modo de ver, ao se engajar no desenvolvimento de atividades com as tecnologias digitais dentro de uma abordagem que valoriza a exploração, os professores tem a oportunidade de aprender sobre tais tecnologias, e de refletir acerca de maneiras para trabalhar diferentes conteúdos dentro de uma mesma proposta, ou ainda, diferentes propriedades relativas a um mesmo conteúdo. Mas para isso, é necessário que os próprios professores tenham a oportunidade de refletir sobre essa abordagem e desenvolver tais atividades, junto a outros educadores matemáticos.

Assim, diante desse movimento evolutivo e da plasticidade do GeoGebra, por causa também de sua acessibilidade dentro dos laboratórios de informática das escolas, e ainda, diante do aumento do interesse em utilizá-lo para abordar conteúdos matemáticos dentro de diferentes níveis de escolaridade, é de suma importância que os professores tenham oportunidades para estudá-lo em atividades que estejam em harmonia com sua dinamicidade, otimizando seu potencial para proporcionar aprendizagem. Ou seja, é relevante que os próprios professores entre si, junto ainda a outros educadores matemáticos que atuam em

\footnotetext{
${ }^{5}$ https://www.geogebra.org/download. Último acesso em 24.05.2017.
} 
outros níveis de escolaridade, constituam ambientes colaborativos de aprendizagem para que eles mesmos possam aprender mutuamente.

Nesse sentido, Rosa, Pazuch e Vanini (2012) defendem uma concepção de formação de professores de Matemática, em que o uso das tecnologias digitais deve ser feito com o propósito de potencializar a aprendizagem matemática, e não apenas como algo mecânico. Ou seja, em sua concepção, eles defendem que o professor deve "pensar-com" a tecnologia, em concordância com o aporte teórico seres-humanos-com-mídias de Borba e Villarreal (2005), no qual a tecnologia não exerce um papel periférico na produção de conhecimento, mas o de protagonista, assim como o sujeito que interage com ela.

Assim, os autores argumentam a favor de que os professores tenham a oportunidade de conceber as tecnologias digitais como transformadoras/potencializadoras da produção de conhecimento matemático e, "posteriormente, busca-se que cada professor ou futuro professor desenvolva o próprio material em consonância com esse processo reflexivo (pensar-com-atecnologia)" (ROSA; PAZUCH; VANINI, 2012, p. 99). Complementando os autores, defendemos a ideia de que os professores podem realizar esse feito de acordo com os contextos de trabalho em que atuam, levando em conta a aprendizagem de seus respectivos alunos.

Em relação aos contextos abordados nesse artigo, destacamos que a parceria com os professores que participaram de nossas ações foi constituída a partir de objetivos em comum e por diferenças de expectativas. Eles participaram voluntariamente de tais ações, tendo a aprendizagem de seus alunos como objetivo comum e também distintas intenções, já que, enquanto alguns objetivavam aprofundar seus estudos em relação ao GeoGebra, pois já tinham um conhecimento prévio, outros almejavam aprender as funcionalidades mais básicas por ainda não terem tido a oportunidade de trabalhar com esse software. Além disso, vale destacar que as horas de trabalho dentro dessas ações foram creditadas no plano de carreira ${ }^{6}$ dos professores cursistas.

As atividades que trabalhamos nas ações foram planejadas com base na abordagem experimental-com-tecnologia, de Borba e Villarreal (2005). Consideramos que as características do GeoGebra estão em sintonia com o que esses autores defendem sobre tal

\footnotetext{
${ }^{6}$ Em relação a de Bauru, contribuiu com pontuação na evolução funcional dos professores, conforme a Resolução SE - 50, de 16.06.2008. Já a de Coimbra, contou pontos para a acreditação, cujos objetivos se referem a promover qualidade nas ações de qualificação docente, contribuir para a regulação externa da formação continuada de professores, garantia de qualidade nos processos de ensino e aprendizagem, etc., conforme consta em Portugal (2014).
} 
abordagem. Nesse sentido, eles argumentam que as atividades desenvolvidas dentro dessa perspectiva possibilitam descobertas matemáticas, construção de conjecturas e um tipo mais "educado" de tentativas e erros. Em relação a isso, eles utilizam de fato esse termo, "educado", pois se referem a tentativas e erros que não são aleatórios, e sim condicionados pelo próprio feedback gerado pela tecnologia com a qual se está interagindo (BORBA; VILLARREAL, 2005). Dentro da visão epistemológica desses autores, as tecnologias não são neutras na produção de conhecimento, mas sim contribuem para transformações no pensamento e fomentam também o surgimento de novos problemas.

E ao se engajarem na realização de tais atividades, os professores que participaram dessas duas ações reconheceram o GeoGebra como um potencializador da aprendizagem matemática, do mesmo modo como concebem Rosa, Pazuch e Vanini (2012). Além disso, tendo em mente seus respectivos contextos de trabalho, paralelamente ao aprofundamento em relação às funcionalidades do software, que vinha acontecendo na realização de cada atividade, eles passaram a tecer críticas às abordagens propostas, reformulando-as de acordo com as necessidades de aprendizagem em suas salas de aula, conforme relatamos com mais detalhes a seguir.

\section{Discussões acerca de atividades experimentais com GeoGebra}

Uma das atividades que foi realizada nos dois contextos abordou o conteúdo função afim (ANEXO). O objetivo era que os professores avaliassem se a abordagem estava adequada para que seus alunos entendessem as propriedades dos parâmetros $a$ e $b$ da função, como eles influenciam no comportamento do gráfico, bem como a relação de dependência entre a variável independente $x$ e a dependente $y=f(x)$. Utilizamos o controle deslizante ${ }^{7}$ para permitir essa variação dos parâmetros e também a planilha para representar os distintos valores assumidos por $x$ e $f(x)$, dentro de $f(x)=a x+b$.

$\mathrm{Na}$ discussão que ocorreu após a realização dessa atividade na ação de Bauru, os professores argumentaram que uma conceituação deveria ser feita antes com os alunos, para que eles posteriormente realizassem essa atividade com o GeoGebra. Na opinião deles, caso isso não fosse feito, os alunos poderiam não ter um proveito significativo por não terem ainda

\footnotetext{
${ }^{7}$ Permite variar o objeto que a ele está vinculado. Nesse caso, por exemplo, os dois parâmetros da função, a e b, foram criados com esse recurso, o que possibilitava que eles fossem variados instantaneamente, dentro de um intervalo qualquer de números, e com incremento opcional.
} 
uma noção sobre o conceito de plano cartesiano e da representação das coordenadas dos pontos nesse plano, uma vez que, para a realização da construção, havia a necessidade do conhecimento prévio acerca desses conceitos. Entretanto, alguns professores, como foi o caso de Douglas ${ }^{8}$, afirmaram que isso não seria um empecilho, pois a conceituação poderia ser feita paralelamente ao desenvolvimento da atividade, sendo que os alunos que apresentassem menos dificuldades já poderiam se antecipar e realizar outras atividades no software.

Alguns professores concordaram, mas outros apontaram que a realidade escolar dificultaria que essa ideia de Douglas fosse colocada em prática. Magali opinou:

[...] mas por exemplo da função, eles têm que saber o que é plano cartesiano, que o ponto tem que ter dois números, senão chega lá eles vão ver aqueles dois números lá na tabelinha de álgebra [janela de álgebra] e não vão entender o que é aquilo...Na minha escola isso é inviável [falando sobre a ideia de Douglas, justificando que são poucos computadores para muitos alunos].

(Professora Magali, Videogravação, 2014).

Outros professores concordaram ainda com esse problema de infraestrutura mencionado por Magali, mas não prolongaram o assunto. Depois, o professor Rodrigo sugeriu que a conceituação fosse feita pelo próprio software, de modo que os alunos observassem a relação entre x e y pela janela de álgebra, mas acrescentou que teria que "usar o datashow, trabalhando passo a passo com eles" (Professor Rodrigo, Videogravação, 2014).

$\mathrm{Na}$ discussão acerca dessa atividade, na ação de Coimbra, os professores sugeriram outros conceitos ainda para serem abordados, como as funções constantes e a interseção do gráfico da função com os eixos coordenados do plano cartesiano. Ruth argumentou que essa abordagem parece propícia para se trabalhar com qualquer conteúdo vinculado à função. Disse que apenas orientaria mais os alunos, principalmente na busca por determinar a intersecção do gráfico da função afim com o eixo y para que eles visualizassem que isso ocorre quando x assume o valor zero. Em suas palavras:

Para qualquer função que se queira trabalhar, eu acho que é um investimento proveitoso, e eles conseguem mais facilmente visualizar interagindo, até com nós, com o quadro [interativo], fazendo variar os parâmetros. Eu só acrescentaria, talvez, interceptaria o gráfico de uma das retas com o eixo dos y, para eles verem e mostraria o rótulo, o valor, para eles verem nessa interseção $y=b$.

(Professora Ruth, Videogravação, 2016).

Complementando, ela disse ainda que colocaria as expressões algébricas das funções junto aos respectivos gráficos na própria janela de visualização, para ficar mais visível a variação para os alunos, inclusive nos casos de paralelismo entre as retas. Nesse momento,

\footnotetext{
${ }^{8}$ Os nomes dos professores foram alterados para preservar suas identidades.
} 
mencionamos aos professores cursistas que isso poderia ser feito arrastando a expressão da função da janela de álgebra para a janela de visualização.

Outros professores argumentaram ainda sobre a necessidade de direcionar melhor o aluno para o objetivo que se quer cumprir com a atividade. Nesse sentido, Cassia destacou que apenas acrescentaria uma folha de orientação, "para tirar conclusões do que estás a ver" (Professora Cassia, Videogravação, 2016). Gisele argumentou que não haveria tempo de trabalhar a construção com os alunos, então seria pertinente uma abordagem com as construções prontas, de modo que as conclusões fossem tiradas junto com eles. Em suas palavras: "Há falta de tempo. Muitas vezes o que nós fazemos é já levar construído e mostrar aos alunos, nem sempre os alunos estão a construir, demora muito mais... Ao invés de fazer um a um, nós projetamos e vamos tirando as conclusões em conjunto" (Professora Gisele, Videogravação, 2016).

Sintetizando, podemos observar que os professores, depois de realizarem essa atividade, em cada curso, fizeram uma análise crítica e teceram uma reflexão conjunta acerca das abordagens propostas, visando a potencialização da aprendizagem de seus alunos, conforme pontuam Rosa, Pazuch e Vanini (2012). Em Bauru, os professores demonstraram maior preocupação com a conceituação prévia necessária para a realização da atividade com o GeoGebra, por considerarem necessário explicar aos alunos os conceitos envolvidos em cada etapa da construção, bem como a noção de plano cartesiano, sobre o posicionamento de pontos nesse plano, etc. Por outro lado, alguns professores argumentaram que isso poderia ser feito com o próprio software, utilizando o projetor multimídia para realizar cada etapa junto com os alunos, como enfatizado pelo professor Rodrigo, durante o curso realizado em Bauru.

Já em Coimbra, os professores propuseram a abordagem de outros conceitos, como a interseção do gráfico da função afim com os eixos coordenados, o estudo das funções constantes e ainda argumentaram sobre a necessidade de maior direcionamento dos alunos ao objetivo de aprendizagem almejado. Além disso, ressaltaram que o professor poderia tirar as conclusões junto com os alunos fazendo cada etapa no projetor multimídia, ou no quadro interativo (lousa digital). Entretanto, diferentemente dos professores de Bauru, os professores da ação de Coimbra fariam isso sem solicitar aos alunos que efetuassem as construções, pois argumentaram que não haveria tempo hábil para isso.

Outra atividade que também foi realizada ao longo dessas duas ações abordou a adição 
de frações próprias, constituída por uma construção pronta extraída do GeoGebra tube ${ }^{9}$, em que, por meio da variação dos controles deslizantes, era possível alterar os numeradores e denominadores das frações e a soma delas. Então o intuito era que os professores avaliassem se a abordagem era apropriada para que seus alunos compreendessem e visualizassem geometricamente essa soma, conforme mostra a Figura 2.

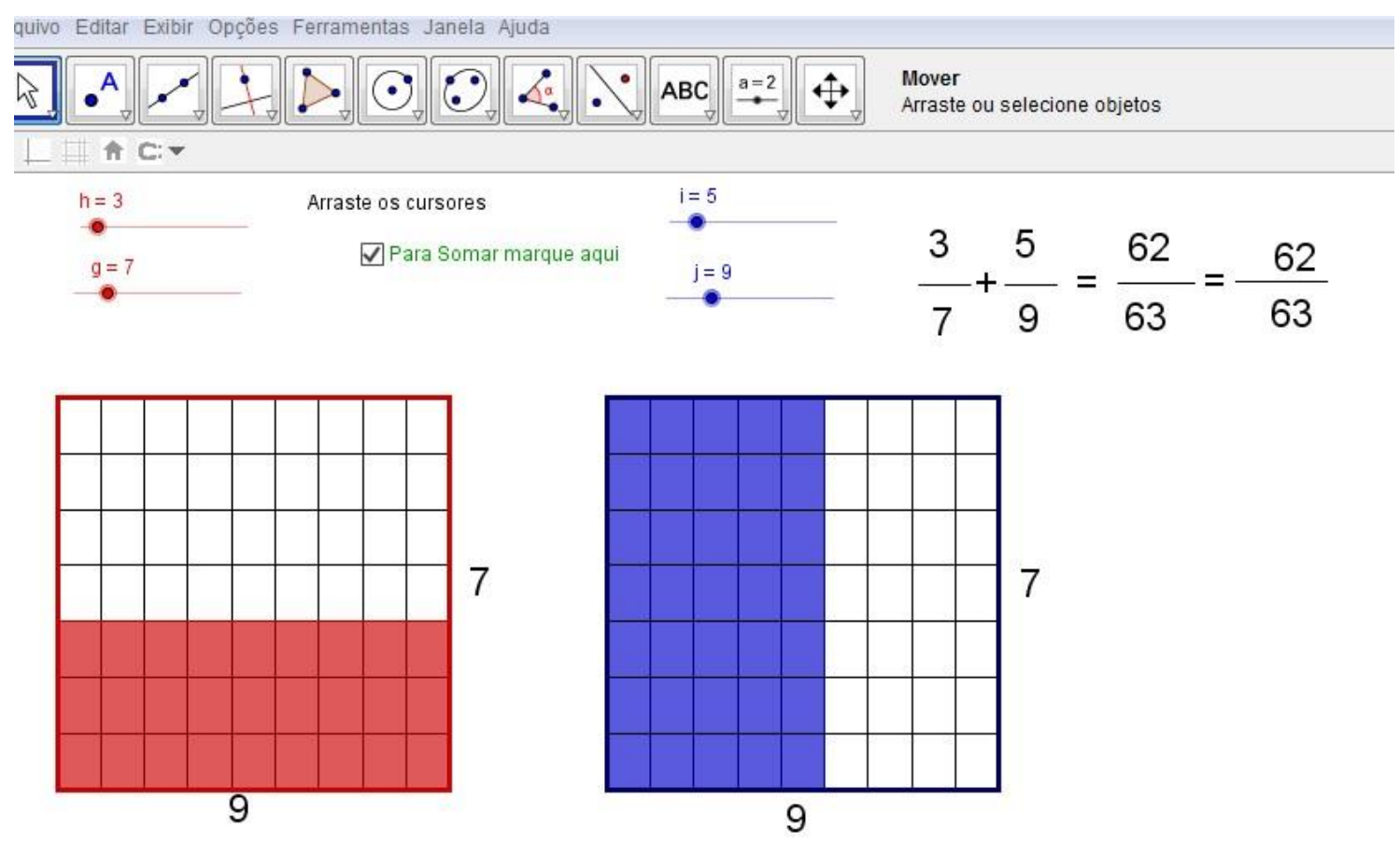

Figura 2 - Atividade de adição de frações Fonte: GeoGebra tube (2014).

No curso que ocorreu em Coimbra, as professoras Gisele e Raquel tentaram entender a lógica utilizada ao apresentarem os retângulos e os números em suas laterais, conforme ilustrado na Figura 2. Além disso, argumentaram que não consideraram viável o fato de o algoritmo utilizado nessa adição não envolver o cálculo do mínimo múltiplo comum (MMC) dos denominadores, uma vez que esse é o método usual pelo qual os alunos aprendem a adicionar e subtrair frações a partir do $5^{\circ}$ ano: "não sei como é que eu faço para fazer isso [inserir o MMC ao invés do produto dos denominadores]", disse Gisele (Videogravação, 2016).

A doutoranda mencionou a ela sobre a possibilidade de calcular o MMC inserindo o comando no campo de entrada do GeoGebra. Ruth ouviu e resolveu seguir essa sugestão. Ela e Olavo tentaram fazer essa programação por algum tempo, durante aquele encontro. Eles

\footnotetext{
9 https://www.geogebra.org/m/K3FvJNcV. Último acesso em 19.04.2017. Nesse caso, diferentemente da atividade anterior, não houve um roteiro impresso, foi apenas solicitado que eles explorassem a construção pronta pensando em aprimorá-la se necessário.
} 
também observaram que os números nas laterais dos retângulos não correspondiam ao que era mostrado na construção, tampouco nas contas. Ou seja, a ideia é que cada bloco represente uma fração, ou seja, de sete blocos horizontais, três estão pintados (primeiro bloco), e a outra fração, que de nove blocos verticais, cinco estão pintados. Mas os números nas laterais não representavam isso, conforme pode-se visualizar na Figura 2.

Assim, ao analisarem a atividade e perceberem que a abordagem não satisfazia o que eles precisavam trabalhar com os alunos em relação a esse conteúdo, os professores começaram a explorar as funcionalidades do software para tentar fazer as alterações que consideravam necessárias. Ou seja, eles estavam explorando e aprendendo uns com os outros sobre tais funcionalidades, em particular acerca da programação realizada para o cálculo da adição, que utilizou a funcionalidade sequência ${ }^{10}$ e outras desconhecidas pela maioria deles, constituindo assim um ambiente colaborativo de aprendizagem, em sintonia com as características pontuadas por Santos e Trocado (2016). Desse modo, eles refletiram acerca de possibilidades de aprendizagem em sala de aula, levando em consideração os conceitos que deveriam ser trabalhados em relação ao conteúdo de adição de frações próprias, e assim, passaram a explorar o GeoGebra para tentar fazer as alterações necessárias, e consequentemente criar um novo material, assim como defendem Rosa, Pazuch e Vanini (2012).

Nesse caso, houve ainda tentativas que perpassaram esse momento. Ruth, por exemplo, elaborou outra abordagem e a apresentou no encontro seguinte, explorando as funcionalidades do protocolo de construção ${ }^{11}$. Ela acrescentou o cálculo feito pelo MMC, modificou o algoritmo para o caso dos denominadores iguais e alterou os retângulos representativos, de acordo com o que eles criticaram ao realizarem essa atividade durante aquele encontro do curso. A abordagem construída por ela, com os cálculos da adição efetuados na linguagem de programação Latex, pode ser visualizada na Figura 3. O algoritmo criado por Ruth está representado pelas frações na cor vermelha:

\footnotetext{
${ }^{10}$ Permite criar uma lista de objetos, que variam dentro de um intervalo pré-determinado.

${ }^{11} \mathrm{O}$ protocolo é uma funcionalidade do GeoGebra que permite visualizar todas as etapas em uma determinada construção, na ordem em que foram executadas.
} 

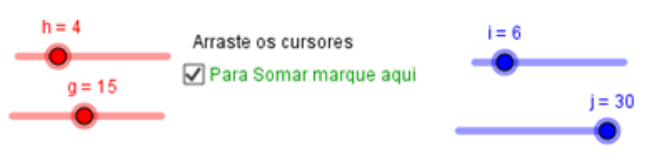

$$
\frac{4}{15}+\frac{6}{30}=\frac{210}{450}=\frac{7}{15}
$$

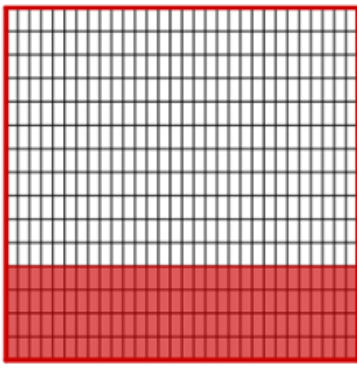

30

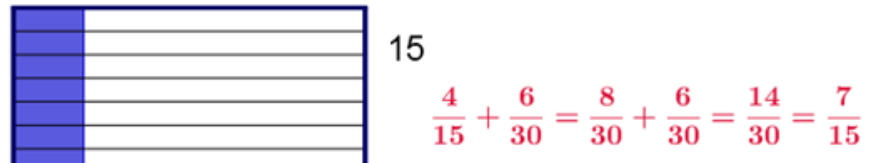

30

Figura 3 - Abordagem adaptada por Ruth

Fonte: Dados da pesquisa de doutorado de Zampieri (2018).

Essa atividade também havia sido abordada na ação de Bauru e gerou outro tipo de discussão. A maioria dos professores argumentou favoravelmente sobre essa atividade, mencionando que cumpria o objetivo que propusemos, que se referia a avaliar se a abordagem era adequada para que seus alunos compreendessem geometricamente a adição de frações próprias. O grupo das professoras Letícia, Paula e Cecília, buscando entender os algoritmos envolvidos em cada etapa dessa adição, abriu o protocolo de construção para começar a explorar o passo a passo. Em seguida, elas chamaram a doutoranda para tirar algumas dúvidas. Para melhor entender o questionamento delas, observemos a Figura 4, apresentada a seguir, que representa o posicionamento exato dos controles deslizantes $g, h, i$ e $j$ no momento em que elas estavam analisando a construção.

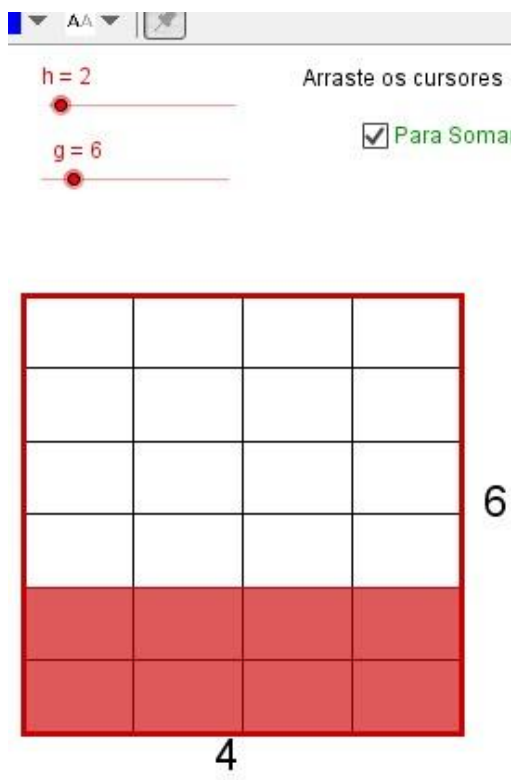

$$
\frac{2}{6}+\frac{1}{4}=\frac{14}{24}=\frac{7}{12}
$$

Figura 4 - Atividade de frações sendo analisada pelo grupo de Letícia Fonte: Dados da pesquisa de doutorado de Zampieri (2018). 
Letícia argumentou que essa abordagem lhe propiciou a seguinte constatação: que há 6 blocos posicionados horizontalmente, dos quais 2 estão pintados, representando a fração 2/6, isso em relação ao primeiro retângulo. Em relação ao segundo, a leitura é que de 4 blocos posicionados verticalmente, 1 deles está pintado, o que equivale à fração 1/4. No entanto, pensando em trabalhar com essa atividade em sala de aula, a professora sugeriu outra abordagem, por meio de frações equivalentes. Ou seja, do total de quadradinhos (24), temos 8 pintados no primeiro retângulo e 6 no segundo, o que equivaleriam às frações 8/24 e 6/24. A sugestão de Letícia era que antes da exibição da resposta 14/24, fosse colocada uma etapa da soma das frações equivalentes, $8 / 24+6 / 24$, para melhorar o entendimento dos alunos. Em suas palavras:

Eu gostaria que aparecesse aqui a fração equivalente...o que que o aluno tem que entender, que aqui é $2 / 6$, porque são 2 coluninhas em um total de 6 . Aqui é por fileira, aqui é uma coluna em um total de quatro. Ou, se eu quiser, eu posso fazer uma outra leitura. Que aqui é 8 por 24 avos. Que no lugar desse 14 por 24 avos, aparecesse 8 por 24 avos mais 6 por 24 avos. Seria importante ele visualizar isso.... Essa etapa não aparece, seria legal que isso aparecesse. É importante ele visualizar...6 vezes quatro, 24. 24 dividido por 6, dá 4, 4 vezes 2 , dá 8 , guarda. Aí por diante [...].

(Professora Letícia, Videogravação, 2014).

Assim, ela passou a estudar o protocolo de construção e as funcionalidades que a possibilitassem incluir essa etapa. Letícia observou que as frações foram colocadas como texto na janela de visualização. Assim, abriu a funcionalidade texto do GeoGebra e tentou digitar os mesmos comandos que já havíamos digitado anteriormente, mas não deu certo. Em seguida, ela tentou entender como a barra da fração havia sido construída, e, ao examinar o protocolo de construção, constatou que foi feita pela funcionalidade segmento. As tentativas de Letícia e de seu grupo despertaram a atenção do professor Lucas, que estava sentado do outro lado da sala, que passou a ajudar o grupo nessa investigação.

Letícia tentou copiar as etapas diretamente do protocolo, mas não obteve sucesso, pois o GeoGebra não permite copiar e colar nessa janela. Em seguida, eles observaram a medida do segmento para cada fração e Letícia, então, criou um segmento com essa mesma medida, escondeu os pontos nas extremidades do segmento e depois começou a explorar um modo de colocar o numerador e o denominador na fração para que representasse 8/24.

Eles examinaram a janela de álgebra e localizaram o numerador 8 , que já havia sido calculado anteriormente no campo de entrada, e então o arrastaram para a janela de visualização em cima do novo segmento criado. Eles fizeram o mesmo procedimento para o denominador. A ideia foi bem sucedida, em partes, porque, conforme os controles deslizantes 
eram variados, podia-se observar a variação dessa primeira fração equivalente, mas a fração teria que ser melhor posicionada e editada para que as letras $s$ e $o$, que representavam esses números na janela de álgebra (e o sinal de igual após essas letras), pudessem ser retirados. Essa primeira tentativa deles pode ser visualizada na Figura 5, a seguir:
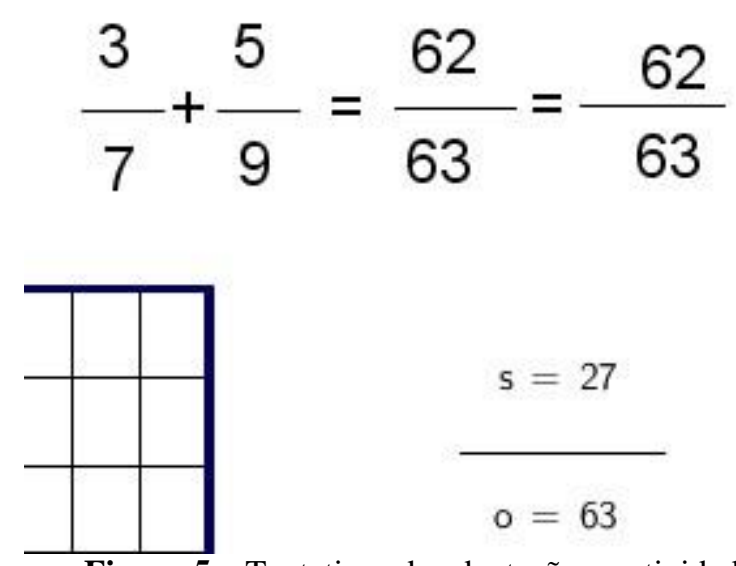

Figura 5 - Tentativas de adaptação na atividade Fonte: Dados da pesquisa de doutorado de Zampieri (2018).

Naquele momento não foi possível a conclusão dessa atividade por parte deles, mas alguns dias depois, Letícia enviou a doutoranda um arquivo no GeoGebra em que tinha realizado essa adaptação, junto com Paula, conforme podemos observar na Figura 6.
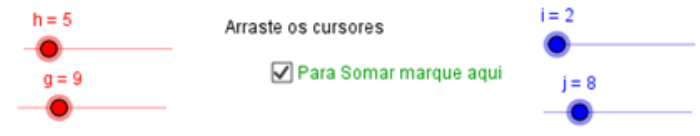

$$
\frac{5}{9}+\frac{2}{8}=\frac{40}{72}+\frac{18}{72}=\frac{58}{72}=\frac{29}{36}
$$
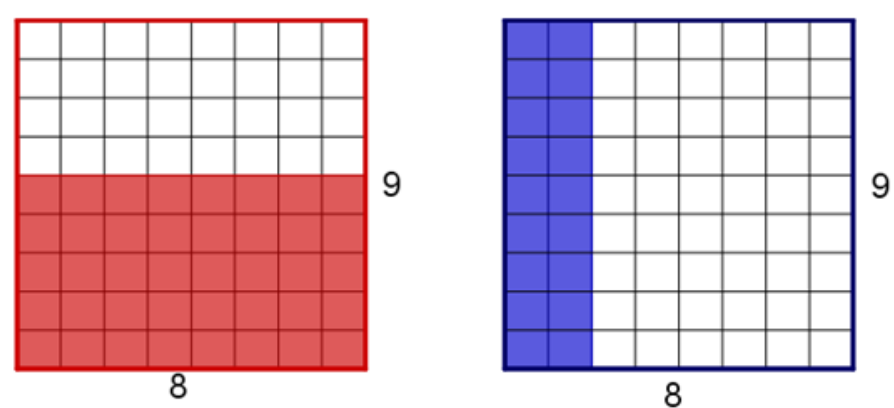

Figura 6 - Adaptação de Letícia e Paula incluindo as etapas com as frações equivalentes Fonte: Dados da pesquisa de doutorado de Zampieri (2018).

De modo geral, nos momentos de realização das atividades e dos respectivos debates entre os professores, em ambas as ações, eles tiveram a oportunidade de estudar distintas funcionalidades do GeoGebra visando atender a objetivos específicos de aprendizagem almejados dentro de cada contexto. Por exemplo, nesse último recorte apresentado, o objetivo era que os professores se concentrassem no aspecto geométrico, para que refletissem se a abordagem era pertinente aos alunos visualizarem a adição de frações, sem necessariamente 
articular com os detalhes envolvidos no cálculo. Entretanto, em ambos os casos, os professores tiveram a preocupação de fazer essa articulação entre o aspecto geométrico e o algébrico, mas, em cada contexto, isso foi pensado de forma diferente, conforme relatado anteriormente.

Ou seja, para efetuar a adição de frações com denominadores diferentes, é usual convertê-las em frações equivalentes com o mesmo denominador. Uma maneira para fazer isso é multiplicar os denominadores e utilizar esse denominador resultante para a conversão das frações e foi esse o algoritmo utilizado pelos programadores que efetuaram essa construção. O grupo de Letícia, do curso de Bauru, concordou com esse modo de efetuar o cálculo, mas apenas pensou que poderia haver mais detalhes, como a exibição de cada fração equivalente, pois isso, na opinião deles, facilitaria a percepção dos alunos acerca do que estavam visualizando. Contudo, esse método nem sempre é o mais usual para efetuar esse cálculo nas aulas de Matemática da Educação Básica, embora seja relativamente simples, conforme concordaram os professores desse curso. Isso acontece porque, a partir do $5^{\mathrm{o}}$ ano, quando os alunos (tanto no Brasil, quanto em Portugal) aprendem o MMC, o algoritmo usual para efetuar a adição de frações se dá pela descoberta do denominador comum por meio do cálculo do MMC entre os denominadores das frações a serem adicionadas.

Foi por terem esse método em mente que os professores de Portugal criticaram a construção. Assim, buscaram estudar mais a fundo as funcionalidades do software para alterar o algoritmo, conforme realizado por completo pela professora Ruth, dias depois. De todo modo, mesmo pensando matematicamente diferente, os professores de ambos os cursos foram além do objetivo sugerido nessa atividade. Esse processo de reflexão ou transformação das atividades possibilitou que os professores aproveitassem a dinamicidade desse software de forma adaptada a seus respectivos contextos, até mesmo nos momentos em que levantaram críticas às atividades sugerindo modificações.

Assim, os professores criaram novos materiais, conforme perspectiva defendida por Rosa, Pazuch e Vanini (2012), na medida em que propuseram, exploraram e realizaram adaptações nas atividades propostas. Isto é, eles realizaram tais adaptações, buscando aproveitar o feedback propiciado por esse software, com o propósito de fomentar as descobertas matemáticas de seus alunos, conforme pontuam Borba e Villarreal (2005) sobre a abordagem experimental-com-tecnologia.

Além disso, assim como argumentam esses autores, outros problemas acabam emergindo com o uso da tecnologia. Nesse caso, com o uso do Geogebra, um problema inicial 
que tinha o propósito de que eles manuseassem a construção já pronta observando se a abordagem geométrica era propícia para a compreensão visual da soma de frações, acabou se tornando um problema desafiador, cujo propósito era o aprimoramento do algoritmo da adição de frações.

Cabe destacar ainda que, ao explorarem o software dentro dessas condições, as tentativas e erros dos professores também foram condicionados pelo feedback do GeoGebra. Porém, não foram referentes à exploração de conjecturas matemáticas, mas sim à exploração dos algoritmos envolvidos nas construções estudadas, com o intuito de promover a aprendizagem de conceitos específicos em suas salas de aula.

Então esse estudo acerca dos mecanismos de funcionamento do software, em ambas as ações, proporcionou muitas reflexões sobre como aproveitá-los em prol da aprendizagem de conteúdos matemáticos, aspectos esses que caracterizam os ambientes colaborativos de aprendizagem, conforme defendem Santos e Trocado (2016).

Diante disso, nas duas ações, tendo em mente o currículo vigente em cada contexto e os perfis de seus alunos, os professores analisaram as atividades buscando aprofundar e refletir, de forma colaborativa, sobre seus conhecimentos acerca do software, culminando então na consolidação de dois ambientes de aprendizagem mútua entre os educadores matemáticos envolvidos.

\section{Considerações finais}

Mesmo acontecendo em contextos distintos, observamos que a realização das atividades com GeoGebra, dentro de um enfoque experimental, promoveu ricas reflexões, oportunizando aos professores que as analisassem colaborativamente e tecessem suas críticas, tendo em mente a aprendizagem de seus alunos. Além disso, oportunizou que eles aprendessem distintas funcionalidades do software GeoGebra. No entanto, eles destacaram também fatores que inviabilizam a aplicação dessas abordagens em sala de aula.

Em Bauru, a questão da infraestrutura ainda é um impeditivo para o uso das tecnologias digitais e esse fator, associado a uma falta de conhecimento de conteúdos prévios, poderia dificultar o trabalho na sala de informática, conforme enfatizou a professora Magali (Videogravação, 2014). Já em Coimbra, os professores se mostram muito preocupados com a falta de tempo hábil para trabalhar um conteúdo por causa do programa curricular ser demasiadamente extenso, sendo que uma atividade em que os alunos mesmos realizassem as 
construções tomaria muito tempo e acabaria atrasando o cumprimento desse programa.

Entretanto, em ambas as circunstâncias, há sugestões para lidar com essas problemáticas, conforme eles mesmos colocaram nos debates. Em Bauru, observamos que alguns professores trabalharam com o GeoGebra em suas salas de aula, pois relataram isso no último encontro que tivemos, destacando os detalhes das construções realizadas com os alunos e nos enviando posteriormente as atividades propostas. Há indícios de que esses professores se apropriaram das funcionalidades desse software e que as reflexões promovidas nessa ação resultaram em práticas concretas em sala de aula (ZAMPIERI; JAVARONI; SILVA, 2016). Já em Coimbra, alguns professores disseram utilizar o GeoGebra, por meio de aulas expositivas com a lousa digital e reiteraram que a visualização propiciada pelo software permite uma aula em que os alunos conseguem interagir formulando conjecturas, ainda que eles mesmos não manuseiem.

Mesmo com essas divergências entre ambas as ações, o fato é que as dinâmicas flexíveis que as permearam, junto ao engajamento e a postura colaborativa dos professores ao estudarem e se aprofundarem nas funcionalidades do software dentro das atividades propostas, culminaram na constituição de ambientes colaborativos de aprendizagem entre os educadores matemáticos envolvidos em cada ação, onde emergiram reflexões sobre o ensino e a aprendizagem de Matemática com o GeoGebra na abordagem de distintos conteúdos, dentro de contextos diversos. Nesse sentido, tais ações possibilitaram que os professores discutissem sobre diferentes modos de trabalhar com esse software em sala de aula, vislumbrando a aprendizagem dos alunos, tendo em conta as particularidades curriculares de cada contexto.

Por fim, independentemente da abordagem que cada professor adote ou que venha a adotar posteriormente em suas salas de aula, consideramos que o envolvimento e o comprometimento deles ao longo das duas ações já possibilitaram reflexões que lhes permitem vislumbrar diferentes modos de potencializar os processos de ensino e aprendizagem da Matemática dentro dos distintos contextos em que atuam. Ou seja, tais ações lhes propiciaram ideias e encorajamento para constituir ambientes colaborativos de aprendizagem também em suas salas de aula, buscando atender especificidades de acordo com os perfis de seus alunos.

\section{Agradecimentos}

O trabalho apresentado foi realizado com o apoio da CAPES, entidade do Governo 
Brasileiro voltado para a formação de recursos humanos.

\section{Referências}

ALMEIDA, M. E. B. Tecnologias na Educação: dos caminhos trilhados aos atuais desafios. Bolema, Rio Claro, v. 21, n. 29, p. 99-129, 2008.

BORBA, M. C.; VILLARREAL, M. Humans-with-Media and the Reorganization of Mathematical Thinking: information and communication technologies, modeling, experimentation and visualization. New York: Springer, v. 39, 2005.

BOTANA, F.; HOHENWARTER, M.; JANICIC, P.; KOVÁCS Z.; PETROVIC, I.; RECIO, T.; WEITZHOFER, S. Automated theorem proving in GeoGebra: Current achievements. Journal of Automated Reasoning, New York, v. 1, n. 55, p. 39-59, 2015.

CHINELLATO, T. G. O uso do computador em escolas públicas estaduais da cidade de Limeira/SP. 2014. 104f. Dissertação (Mestrado em Educação Matemática) - Instituto de Geociências e Ciências Exatas, Universidade Estadual Paulista "Júlio de Mesquita Filho", Rio Claro, 2014.

GEOGEBRA. Downloads. Disponível em: <https://www.geogebra.org/download>. Acesso em: 25 mai. 2017.

GEOGEBRA. GeoGebra tube. Disponível em: <https://www.geogebra.org/material/show/id/ 1303715>. Acesso em: 25 mai. 2017.

JAVARONI, S. L; ZAMPIERI, M. T. O uso das TIC nas práticas dos professores de Matemática da rede básica de ensino. Bolema, Rio Claro, v. 29, n. 53, p. 998-1022, 2015.

OLIVEIRA, F. T. A inviabilidade do uso das tecnologias da informação e comunicação no contexto escolar: o que contam os professores de Matemática? 2014. 169f. Dissertação (Mestrado em Educação Matemática) - Instituto de Geociências e Ciências Exatas, Universidade Estadual Paulista "Júlio de Mesquita Filho", Rio Claro, 2014.

PERALTA, P. F. Utilização das Tecnologias Digitais por Professores de Matemática: um olhar para a região de São José do Rio Preto. 2015. 119f. Dissertação (Mestrado em Educação Matemática) Instituto de Geociências e Ciências Exatas, Universidade Estadual Paulista "Júlio de Mesquita Filho", Rio Claro, 2015.

PORTO EDITORA. Adição de frações, 2013. Disponível em: <https://www.geogebra.org/m/K3 FvJNcV>. Acesso em: 19 abr. 2017.

PORTUGAL. Diário da República. Estabelece o regime jurídico da formação contínua de professores e define sistema de coordenação, administração e apoio. 2014. Disponível em: <http://www. fenprof.pt/Download/FENPROF/SM_Doc/Mid_204/Doc_8202/Anexos/Regime_Juridico_da_formaca o_continua_de_professores.pdf >. Acesso em: 19 abr. 2017.

ROSA, M.; PAZUCH, V.; VANINI, L. Tecnologias no ensino de Matemática: a concepção de cyberformação como norteadora do processo educacional. In: XI ENCONTRO GAÚCHO DE EDUCAÇÃO MATEMÁTICA, 11., 2012, Lajeado/RS. Anais... Lajeado/RS: [s.n.], 2012. p. 1-7.

SANTOS, V.; QUARESMA, P. Plataforma Colaborativa para a Geometria. In: Indagatio Didactica, Aveiro (Portugal), v. 5, n. 1, p. 31-39, 2013.

SANTOS, J. M.; TROCADO, A. E. B. GeoGebra as a learning Mathematical Environment. In: 
Revista do Instituto GeoGebra Internacional de São Paulo, São Paulo, v. 5, n. 1, p. 05-22, 2016.

SÃO PAULO. Secretaria da Educação do Estado de São Paulo. Resolução SE - 50 de 16 de junho de 2008. Dispõe sobre a Evolução Funcional dos integrantes do Quadro de Apoio Escolar da Secretaria de Estado da Educação. Disponível em: <http://siau.edunet.sp.gov.br/ItemLise/arquivos/50_08.HTM? Time=19/04/2017\%2017:35:01>. Acesso em: 19 abr. 2017.

ZAMPIERI, M. T. Ações colaborativas de formação continuada de educadores matemáticos: saberes constituídos e mobilizados. 2018. 280f. Tese (Doutorado em Educação Matemática) - Instituto de Geociências e Ciências Exatas, Universidade Estadual Paulista "Júlio de Mesquita Filho", Rio Claro, 2018.

ZAMPIERI, M. T.; JAVARONI, S. L.; SILVA, J. M. M. C. Formação continuada em ambientes de geometria dinâmica e seu impacto em sala de aula. In: XXVII Seminário de Investigação em Educação Matemática, 27.., 2016, Porto/Portugal. Anais... Porto/Portugal: [s.n.], 2016. p. 459-472.

Submetido em 20 de Junho de 2017. Aprovado em 10 de Janeiro de 2018. 


\section{Anexo}

\section{Roteiro - Atividade com função afim no GeoGebra}

1 - Clicar na penúltima janela no canto superior, chamado "controle deslizante". Depois, dar um clique no meio da tela. Em "nome" escrever "a", e no intervalo, colocar de10 a 10 e incremento 0,1 .

2 - Depois, repetir esse processo, de forma análoga, ao invés de "a" em nome, colocar "b", com as mesmas medidas do item 1.

3 - No campo "entrada", digitar $\mathrm{f}(\mathrm{x})=$ ax. Aparecerá o gráfico. Em seguida, no campo "entrada", digitar $\mathrm{g}(\mathrm{x})=\mathrm{ax}+\mathrm{b}$. Aparecerá o gráfico dessa função.

4 - Pensando na aplicação em sala de aula, você pode desenvolver com os alunos habilidades relacionadas ao estudo do comportamento destes dois gráficos, ou seja, que eles consigam identificar as variáveis dependentes e as independentes e que entendam os significados das variações dos parâmetros a e b. Assim, poderão ser feitas perguntas como:

a) Variando o parâmetro a, o que você observa em cada gráfico? E variando esse parâmetro, o que você observa na distância entre as duas retas? A partir dessa observação, em sua opinião, qual é o significado geométrico de a?

b) Variando o parâmetro b, o que você observa em cada gráfico? E na distância entre eles? A partir dessa observação, em sua opinião, qual é o significado de b?

5 - Clique em "Exibir" na barra de ferramentas, e depois clique na opção "planilha". Ao abrir a planilha no canto direito, digite $\mathrm{X}$ (maiúsculo), na célula $\mathrm{A} 1, \mathrm{~F}(\mathrm{X})$ (em maiúsculo) na célula $B 1$ e $G(X)$ (em maiúsculo) na célula $C 1$.

6 - Na coluna " $X$ " digite os valores de -4 a 10. Na célula B2, digite a fórmula f(A2) e dê enter. Depois arraste essa fórmula para as outras células B.

7 - Na célula C2, digite a fórmula g(A2) e dê enter. Depois arraste essa fórmula para as outras células $\mathrm{C}$.

8 - Voltando a pensar em sala de aula, solicite aos alunos que variem o parâmetro a e que observem o que acontece com as três colunas da planilha. Solicite a eles que identifiquem as variáveis dependentes e independentes e que justifiquem pautados no que estão visualizando.

9 - O que acontece com a posição entre as duas retas quando o valor de b é muito próximo de 0 ?

10 - Manipulando os parâmetros, você consegue deixar as retas na posição vertical? 
Esboce uma explicação para essa situação.

Referências:

EDUC. FC. Função linear afim: equação de rectas. Disponível em: <http://www.educ.fc.ul.pt/icm/icm2000/icm28/func/flrec.htm>. Acesso em: 25 nov. 2017.

PUCMINAS. Capítulo 1: Retas e funções lineares. Disponível em: <http://www.matematica.pucminas.br/profs/web_fabiano/calculo1/lineares.pdf>. Acesso em: 25 nov. 2017.

\section{Perguntas para debate coletivo}

1 - Esse tipo de atividade poderia ser utilizado para introduzir o conteúdo "funções afins" ou para ser desenvolvida depois que os alunos já tiveram um contato prévio com o conteúdo?

2 - Que tipo de sugestões você daria para adaptar essa atividade para uma situação de seu interesse em sala de aula? Que modificações você faria?

3 - Especifique as potencialidades e limitações do GeoGebra para esse tipo de atividade? 